\title{
A General Fixed Point Theorem for Multivalued Mappings That Are Not Necessarily Contractions and Applications
}

\author{
Abdul Latif ${ }^{1}$ and Dinh The Luc ${ }^{2}$ \\ ${ }^{1}$ Department of Mathematics, King Abdulaziz University, P.O. Box 80203, Jeddah 21589, Saudi Arabia \\ ${ }^{2}$ Avignon University, LMA-EA2151, 84000 Avignon, France
}

Correspondence should be addressed to Abdul Latif; alatif@kau.edu.sa

Received 13 May 2014; Accepted 5 June 2014; Published 17 June 2014

Academic Editor: Jen-Chih Yao

Copyright (C) 2014 A. Latif and D. T. Luc. This is an open access article distributed under the Creative Commons Attribution License, which permits unrestricted use, distribution, and reproduction in any medium, provided the original work is properly cited.

We prove a general theorem on fixed points of multivalued mappings that are not necessarily contractions and derive a number of recent contributions on this topic for contraction mappings.

\section{Introduction}

One of the most powerful results of functional analysis is the Banach contraction principle which states that if $f$ is a contraction on a complete metric space $(X, d)$, that is, $d(f(x), f(y)) \leq r d(x, y)$ for every $x, y \in X$ and some fixed $r \in(0,1)$, then $f$ has a unique fixed point. Moreover, that unique point can be approximately computed by a very simple iterative procedure. Namely, starting from any point $x_{0} \in X$, the sequence obtained by $x_{n+1}=f\left(x_{n}\right)$ for $n \geq 0$ converges to the fixed point. Numerous applications and generalizations of this principle are known in nonlinear analysis (see [1-5] and many references given in these).

Since the publication of the Banach principle, there have been a huge number of research papers devoted to its generalization. Among them, the extension to set-valued mappings receives a lot of attention. The works by Nadler Jr. [6] and Markin [7] are among the first efforts in this direction, in which the Hausdorff distance is used to define contraction set-valued mappings. Further significant generalizations are presented in [8-19] and many others.

The aim of the present paper is to give a general condition for existence of fixed points of set-valued mappings that are not necessarily contractions. The novelty of our approach is the relaxation of requirements for a point to be chosen at current iteration to lie in the image of the point at the preceding iteration during the construction of a sequence of points that converges to a fixed point. Another novelty resides in the use of two different functions to estimate the distance between two consecutive points of the procedure, which makes our result flexible and allows us to deduce a number of important theorems of the aforementioned works for contraction mappings.

\section{The Main Result}

Throughout this section, we assume that $(X, d)$ is a complete metric space. Given a nonempty set $A \subseteq X$, the distance from a point $a \in X$ to $A$ is denoted by $d(a, A)$ and defined by $d(a, A)=\inf _{x \in A} d(a, x)$.

Theorem 1. Let $F$ be a set-valued map on $X$ with values in the space of nonempty closed subsets of $X$. Assume that the function $d(x, F(x))$ is lower semicontinuous on $X$ and that there are positive valued functions $\phi$ and $\psi$ on $[0, \infty)$ such that

$$
\text { (i) } \lim \sup _{s \rightarrow t^{+}}(\phi(s) / \psi(s))<1 \text { for each } t \geq 0 \text {. }
$$

Then $F$ has a fixed point if either of the following conditions holds:

(A) $\liminf _{s \rightarrow 0} \psi(s)>0$, and for every $x \in X$ there is some $y \in X$ such that

(ii) $d(y, F(y)) \leq \phi(d(x, F(x))) d(x, y) \leq \psi(d(x$, $F(x))) d(x, y) \leq d(x, F(x))$

(B) $\lim \sup _{s_{n} \rightarrow t}\left(\phi\left(s_{n}\right) / \psi\left(s_{n}\right)\right)<1$ whenever $\lim _{s_{n} \rightarrow t} \psi\left(s_{n}\right)<1$ for $t>0$, and there is some 
$a>0$ such that for every $x \in X$ with $x \notin F(x)$ there is some $y \in X$ satisfying

(iii) $d(x, y) \geq d(x, F(x))$ and $\psi(d(x, y)) \geq a$;

(iv) $d(y, F(y)) \leq \phi(d(x, y)) d(x, y) \leq \psi(d(x, y)) d(x$, $y) \leq d(x, F(x))$.

Proof. We wish to construct a Cauchy sequence $\left\{x_{n}\right\}_{n=0}^{\infty}$ such that the sequence $\left\{d\left(x_{n}, F\left(x_{n}\right)\right)\right\}_{n=0}^{\infty}$ converges to 0 . This, of course, proves the theorem because the limit $\bar{x}$ of the sequence $\left\{x_{n}\right\}_{n=0}^{\infty}$ satisfies

$$
d(\bar{x}, F(\bar{x})) \leq \lim _{n \rightarrow \infty} d\left(x_{n}, F\left(x_{n}\right)\right)=0,
$$

which shows that $\bar{x} \in F(\bar{x})$, because the set $F(\bar{x})$ is closed.

We assume (A) first. Let us start with any point $x_{0} \in X$. If $x_{0} \in F\left(x_{0}\right)$, we are done. If not, we choose $x_{1} \in X$ as given in (ii):

$$
\begin{aligned}
& d\left(x_{1}, F\left(x_{1}\right)\right) \leq \phi\left(d\left(x_{0}, F\left(x_{0}\right)\right)\right) d\left(x_{0}, x_{1}\right), \\
& \psi\left(d\left(x_{0}, F\left(x_{0}\right)\right)\right) d\left(x_{0}, x_{1}\right) \leq d\left(x_{0}, F\left(x_{0}\right)\right) .
\end{aligned}
$$

Similarly, restarting from $x_{1}$ we choose $x_{2} \in X$ satisfying the inequalities in (ii) and continue this process either to arrive at a fixed point of $F$ or to obtain a sequence of $x_{n}^{\prime}$ s such that $x_{n} \notin F\left(x_{n}\right)$ and

$$
\begin{aligned}
d\left(x_{n+1}, F\left(x_{n+1}\right)\right) & \leq \phi\left(d\left(x_{n}, F\left(x_{n}\right)\right)\right) d\left(x_{n}, x_{n+1}\right) \\
& \leq \psi\left(d\left(x_{n}, F\left(x_{n}\right)\right)\right) d\left(x_{n}, x_{n+1}\right) \\
& \leq d\left(x_{n}, F\left(x_{n}\right)\right)
\end{aligned}
$$

for every $n \geq 1$. Observe that $\phi\left(d\left(x_{n}, F\left(x_{n}\right)\right)\right)>0$ because, otherwise, in view of (3) one would have $x_{n+1} \in F\left(x_{n+1}\right)$, which is a contradiction. Hence, $\psi\left(d\left(x_{n}, F\left(x_{n}\right)\right)\right)>0$. It follows that

$$
d\left(x_{n+1}, F\left(x_{n+1}\right)\right) \leq \frac{\phi\left(d\left(x_{n}, F\left(x_{n}\right)\right)\right)}{\psi\left(d\left(x_{n}, F\left(x_{n}\right)\right)\right)} d\left(x_{n}, F\left(x_{n}\right)\right) .
$$

In view of (3), the sequence $\left\{d\left(x_{n}, F\left(x_{n}\right)\right)\right\}_{n=0}^{\infty}$ is decreasing and hence decreasingly converges to some limit $\delta \geq 0$. Actually $\delta=0$ because otherwise, by passing to the limit on both sides of (4) for $x_{n_{k}}$ instead of $x_{n}$ when $k$ tends to $\infty$ and by (i), we would obtain

$$
\delta \leq \delta \limsup _{k \rightarrow \infty} \frac{\phi\left(d\left(x_{n_{k}}, x_{n_{k}+1}\right)\right)}{\psi\left(d\left(x_{n_{k}}, x_{n_{k}+1}\right)\right)}<\delta,
$$

which is a contradiction. The first part of hypothesis (A) and (3) imply

$$
\lim _{n \rightarrow \infty} d\left(x_{n}, x_{n+1}\right)=0 .
$$

We claim that this sequence is a Cauchy sequence. Indeed, by (i) and the first hypothesis of (A), there are some $q \in(0,1)$, $\alpha>0$, and $N \geq 1$ such that

$$
\begin{gathered}
\frac{\phi\left(d\left(x_{n}, F\left(x_{n}\right)\right)\right)}{\psi\left(d\left(x_{n}, F\left(x_{n}\right)\right)\right)} \leq q, \\
\psi\left(d\left(x_{n}, F\left(x_{n}\right)\right)\right) \geq \alpha \quad \forall n \geq N .
\end{gathered}
$$

Combining this with (3) yields

$$
\begin{aligned}
d\left(x_{n}, x_{n+m}\right) \leq & d\left(x_{n}, x_{n+1}\right)+\cdots+d\left(x_{n+m-1}, x_{n+m}\right) \\
\leq & \frac{1}{\alpha}\left[d\left(x_{n}, F\left(x_{n}\right)\right)\right. \\
& \left.\quad+\cdots+d\left(x_{n+m-1}, F\left(x_{n+m-1}\right)\right)\right] \\
\leq & \frac{1}{\alpha} d\left(x_{n}, F\left(x_{n}\right)\right)\left[1+q+\cdots+q^{m-1}\right] \\
\leq & \frac{1-q^{m}}{\alpha(1-q)} d\left(x_{n}, F\left(x_{n}\right)\right)
\end{aligned}
$$

for $n \geq N$ and $m \geq 1$. Since the sequence $\left\{d\left(x_{n}, F\left(x_{n}\right)\right)\right\}_{n=0}^{\infty}$ converges to 0 as $n$ tends to $\infty$, we deduce that the sequence $\left\{x_{n}\right\}_{n=0}^{\infty}$ is Cauchy and hence it converges to some limit as requested.

We now assume (B). By the same argument as mentioned above, we may find either a fixed point of $F$ or a sequence of $x_{n}^{\prime}$ s such that $x_{n} \notin F\left(x_{n}\right)$ and

$$
\begin{aligned}
a & \leq \psi\left(d\left(x_{n}, x_{n+1}\right)\right), \\
d\left(x_{n+1}, F\left(x_{n+1}\right)\right) & \leq \phi\left(d\left(x_{n}, x_{n+1}\right)\right) d\left(x_{n}, x_{n+1}\right) \\
& \leq \psi\left(d\left(x_{n}, x_{n+1}\right)\right) d\left(x_{n}, F\left(x_{n}\right)\right) \\
& \leq d\left(x_{n}, F\left(x_{n}\right)\right)
\end{aligned}
$$

in which $\phi\left(d\left(x_{n}, x_{n+1}\right)\right)>0$ and $\psi\left(d\left(x_{n}, x_{n+1}\right)\right)>0$ for every $n \geq 1$ and deduce that

$$
d\left(x_{n+1}, F\left(x_{n+1}\right)\right) \leq \frac{\phi\left(d\left(x_{n}, x_{n+1}\right)\right)}{\psi\left(d\left(x_{n}, x_{n+1}\right)\right)} d\left(x_{n}, F\left(x_{n}\right)\right) .
$$

From (10) we know that the sequence $\left\{d\left(x_{n}, F\left(x_{n}\right)\right)\right\}_{n=0}^{\infty}$ is decreasing and hence decreasingly converges to some limit $\delta \geq 0$. Then, in view of (10) and (9), the inferior limit of the sequence $\left\{d\left(x_{n}, x_{n+1}\right)\right\}_{n=0}^{\infty}$ is finite. Let us denote by $\left\{d\left(x_{n_{k}}, x_{n_{k}+1}\right)\right\}_{k=0}^{\infty}$ a subsequence such that

$$
\theta=\lim _{k \rightarrow \infty} d\left(x_{n_{k}}, x_{n_{k}+1}\right)=\liminf _{n \rightarrow \infty} d\left(x_{n}, x_{n+1}\right) .
$$

We easily have $\delta \leq \theta \leq \delta / a$. We wish to prove that these values are all equal to zero.

Claim $1(\delta=\theta)$. Suppose to the contrary that $\delta<\theta$. Then $\delta>0$. We choose a small $\epsilon>0$ such that $\delta+\epsilon<\theta-\epsilon$. Then there is some $N>1$ such that

$$
d\left(x_{n}, F\left(x_{n}\right)\right) \leq \delta+\epsilon<\theta-\epsilon \leq d\left(x_{n}, x_{n+1}\right) \quad \text { for } n \geq N .
$$

This and (10) yield

$$
\begin{aligned}
\psi\left(d\left(x_{n}, x_{n+1}\right)\right)(\theta-\epsilon) & \leq \psi\left(d\left(x_{n}, x_{n+1}\right)\right) d\left(x_{n}, x_{n+1}\right) \\
& \leq d\left(x_{n}, F\left(x_{n}\right)\right) \leq \delta+\epsilon
\end{aligned}
$$

which implies that $\limsup _{n \rightarrow \infty} \psi\left(d\left(x_{n}, x_{n+1}\right)\right)<1$. By using the first part of (B) and by passing to the limit in (11) for $x_{n_{k}}$ 
instead of $x_{n}$ when $n_{k}$ tends to $\infty$, we arrive at the following inequality:

$$
\begin{aligned}
\delta & =\lim _{k \rightarrow \infty} d\left(x_{n_{k}}, F\left(x_{n_{k}}\right)\right) \\
& \leq \limsup _{k \rightarrow \infty} \frac{\phi\left(d\left(x_{n_{k}}, x_{n_{k}+1}\right)\right)}{\psi\left(d\left(x_{n_{k}}, x_{n_{k}+1}\right)\right)} d\left(x_{n_{k}}, F\left(x_{n_{k}}\right)\right) \\
& \leq \delta \limsup _{k \rightarrow \infty} \frac{\phi\left(d\left(x_{n_{k}}, x_{n_{k}+1}\right)\right)}{\psi\left(d\left(x_{n_{k}}, x_{n_{k}+1}\right)\right)}<\delta,
\end{aligned}
$$

which is a contradiction. By this, $\delta=\theta$.

Claim $2(\delta=\theta=0)$. Suppose to the contrary that $\delta>0$. According to (iii),

$$
\delta \leq d\left(x_{n}, F\left(x_{n}\right)\right) \leq d\left(x_{n}, x_{n+1}\right),
$$

which means that $\lim _{k \rightarrow \infty} d\left(x_{n_{k}}, x_{n_{k}+1}\right)=\delta^{+}$. Due to (i), we deduce from (9) that

$$
\delta \leq \delta \limsup _{k \rightarrow \infty} \frac{\phi\left(d\left(x_{n_{k}}, x_{n_{k}+1}\right)\right)}{\psi\left(d\left(x_{n_{k}}, x_{n_{k}+1}\right)\right)}<\delta,
$$

which, again, is a contradiction.

Claim 3. The sequence $\left\{x_{n}\right\}_{n=0}^{\infty}$ is a Cauchy sequence. In view of Claim 2 and (iii), the sequence $\left\{d\left(x_{n}, x_{n+1}\right)\right\}_{n=0}^{\infty}$ converges to zero. By (i), there are some $q \in(0,1)$ and $N>0$ such that

$$
\frac{\phi\left(d\left(x_{n}, x_{n+1}\right)\right)}{\psi\left(d\left(x_{n}, x_{n+1}\right)\right)} \leq q \quad \forall n \geq N
$$

It remains to apply the same argument as in the case of condition (A) to conclude the proof.

We close up this section by observing that in the literature on fixed points of contraction mappings it is frequently required that the element $y$ in conditions (A) and (B) belongs to $F(x)$, in which case the hypothesis $d(x, y) \geq d(x, F(x))$ (condition (iii)) is evidently satisfied. The fact that $y$ is allowed to be chosen outside $F(x)$ is extremely important in computing fixed points of mappings that are not contractive at certain points. Below is an example to illustrate this.

Example 2. Consider a discrete metric space $X$ consisting of five points: $0,0.25,0.5,0.75$, and 1 of the real line $\mathbb{R}$ equipped with the usual distance. Define a map $F: X \rightarrow X$ by

$$
\begin{gathered}
F(0)=1, \quad F(0.25)=0.75, \quad F(0.5)=0.5, \\
F(0.75)=0.5, \quad F(1)=0 .
\end{gathered}
$$

It is clear that $F$ is not a contraction. If we start at $x_{0}=0$ and apply the classical algorithm $x_{n+1}=F\left(x_{n}\right)$ for $n \geq 0$, then it produces an infinite loop and we never get the fixed point. In order to avoid cycling, let us define two functions $\phi$ and $\psi$ on $[0, \infty)$ by

$$
\begin{aligned}
& \phi(t)= \begin{cases}\frac{1}{3} & \text { if } 0 \leq t \leq \frac{3}{4} \\
t-\frac{5}{12} & \text { if } t \geq \frac{3}{4}\end{cases} \\
& \psi(t)= \begin{cases}\frac{2}{3} & \text { if } 0 \leq t \leq \frac{3}{4} \\
t-\frac{1}{12} & \text { if } t \geq \frac{3}{4}\end{cases}
\end{aligned}
$$

Now we start with $x_{0}=0$. If we take $y=F\left(x_{0}\right)$, then neither (ii) nor (iv) is satisfied. Let us choose $x_{1}=0.75$ the closest element to $F\left(x_{0}\right)$ for which condition (ii) of Theorem 1 is fulfilled. In the next iteration we take $x_{2}=0.5=F\left(x_{1}\right)$ that satisfies the above-mentioned condition too. This $x_{2}$ is a fixed point of $F$.

\section{Particular Cases}

In this section we deduce a number of results in recent publications from the main theorem given in the preceding section. The first corollary is Mizoguchi-Takahashi's theorem (Theorem 5, [18]) which according to Suzuki [19] is a real generalization of Nadler's theorem [6]. We recall that the Hausdorff metric induced by $d$ is given by

$$
h(A, B)=\max \left\{\sup _{a \in A} d(a, B) ; \sup _{b \in B} d(b, A)\right\}
$$

for any two subsets $A$ and $B$ of $X$.

Corollary 3. Let $F$ be a set-valued map on $X$ with values in the space of nonempty closed bounded subsets of $X$. Assume that there is a function $\phi:[0, \infty) \rightarrow[0,1)$ satisfying

$$
\begin{aligned}
& \text { (M1) } \lim \sup _{s \rightarrow t^{+}} \phi(s)<1 \text { for each } t \geq 0 \\
& \text { (M2) } h(F(x), F(y)) \leq \phi(d(x, y)) d(x, y) \text { for all } x, y \in X .
\end{aligned}
$$

Then $F$ has a fixed point.

Proof. Our aim is to apply Theorem 1 . Towards this end we construct a function $\psi$ and prove that condition (B) is satisfied. Let $\psi:[0, \infty) \rightarrow[0,1)$ be defined by

$$
\psi(t)= \begin{cases}\frac{1}{2} & \text { if } \phi(t)<\frac{1}{3} \\ \sqrt{\phi(t)} & \text { if } \phi(t) \geq \frac{1}{3} .\end{cases}
$$

We check the hypotheses of Theorem 1 . First, the function $d(x, F(x))$ is Lipschitz and hence lower semicontinuous because

$$
\begin{aligned}
& |d(x, F(x))-d(y, F(y))| \\
& \quad \leq d(x, y)+h(F(x), F(y)) \leq 2 d(x, y)
\end{aligned}
$$

due to condition (M2) and the fact that $\phi(t)<1$. 
Second, for every $s \geq 0$, we have $\phi(s) / \psi(s) \leq \max \{2 / 3$, $\sqrt{\phi(s)}\}$. This and (M1) imply the first part of (B) and condition (i) of Theorem 1.

Third, by the definition of $\psi$, condition (iii) (Theorem 1 ) is satisfied for every $x \in X$ and $y \in F(x)$ if we choose $a=1 / 3$.

And finally, the first inequality of (iv) of Theorem 1 holds for any $y \in F(x)$ because of the Lipschitz condition (M2). For the second inequality it suffices to choose $y \in F(x)$ so that $\alpha d(x, y) \leq d(x, F(x))$, where $\alpha=$

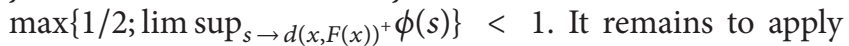
Theorem 1 to complete the proof.

As far as we know, most important generalizations of fixed point conditions for contraction mappings without using Hausdorff distance belong to Ciric in his recent works $[9,10]$. Let us see how to deduce them from Theorem 1.

Corollary 4 (Theorems 2.1 and 2.2 of [10] and Theorem 5 of [9]). Let $F$ be a set-valued map on $X$ with values in the space of nonempty closed subsets of $X$. Assume that the function $d(x, F(x))$ is lower semicontinuous on $X$ and that there is a function $\phi:[0, \infty) \rightarrow[\alpha, 1)$ for some $\alpha \in(0,1)$, which satisfies limsup $\operatorname{sut}_{s \rightarrow t^{+}} \phi(s)<1$ for each $t \geq 0$. Assume further that one of the following conditions holds.

(C1) For every $x \in X$ there is some $y \in F(x)$ such that

$$
\begin{aligned}
& \sqrt{\phi(d(x, F(x)))} d(x, y) \leq d(x, F(x)), \\
& d(y, F(y)) \leq \phi(d(x, F(x))) d(x, y) .
\end{aligned}
$$

(C2) For every $x \in X$ there is some $y \in F(x)$ such that

$$
\begin{aligned}
& \sqrt{\phi(d(x, y))} d(x, y) \leq d(x, F(x)), \\
& d(y, F(y)) \leq \phi(d(x, y)) d(x, y) .
\end{aligned}
$$

(C3) In this condition $\alpha=0$ and for every $x \in X$ there is some $y \in F(x)$ such that

$$
\begin{gathered}
d(x, y) \leq(2-\phi(d(x, y))) d(x, F(x)), \\
d(y, F(y)) \leq \phi(d(x, y)) d(x, y) .
\end{gathered}
$$

Then F has a fixed point.

Proof. Under (C1) and (C2), set $\psi(t)=\sqrt{\phi(t)}$ for every $t \geq$ 0 and, under $(\mathrm{C} 3)$, set $\psi(t)=1 /(2-\phi(t))$. And then apply Theorem 1. Note that $\psi(t) \geq \sqrt{\alpha}$ under (C1) and (C2) and $\psi(t) \geq 1 / 2$ under (C3) for every $t \geq 0$, and so the first part of (A) and (iii) of Theorem 1 hold true. Other conditions of Theorem 1 are almost immediate.

Other important results such as Theorems 6 and 7 of [9], Theorem 2 of [12], and Theorems 3 and 4 of [14] can also be obtained from Theorem 1 by a similar argument. Of course, when $F$ is single valued, the conditions of all above cited theorems imply that $F$ is a contraction, and so they are not applicable to noncontraction mappings.
We close up this section by discussing the following very recent result of $\mathrm{Du}$ and Khojasteh [20, Theorem 15]. Let $F$ be defined on $X$ with values in the space of nonempty bounded and closed subsets of $X$. Let $\phi$ satisfy condition (M1) of Corollary 3. Assume further that there is a function $\alpha: X \times X \rightarrow[0, \infty)$ such that one has the following.

(D1) $\alpha(x, y) d(y, F(y)) \leq \phi(d(x, y)) d(x, y)$ for every $y \in$ $F(x)$.

(D2) If $x \in X$ and $y \in T(x)$ satisfy $\alpha(x, y) \geq 1$, then $\alpha(y, z) \geq 1$ for all $z \in F(y)$.

(D3) There is $x_{0} \in X$ and $x_{1} \in F\left(x_{0}\right)$ such that $\alpha\left(x_{0}, x_{1}\right) \geq$ 1.

(D4) One of the following conditions holds:

(H1) $F$ is continuous in the sense that $h\left(F\left(x_{n}\right), F(x)\right)$ converges to 0 as soon as $x_{n}$ tends to $x$;

(H2) the graph of $F$ is closed;

(H3) the function $d(x, F(x))$ is lower semicontinuous;

(H4) for every sequence $\left\{x_{n}\right\}_{n=0}^{\infty}$ converging to $x$ and with $\alpha\left(x_{n}, x_{n+1}\right) \geq 1, x_{n+1} \in F\left(x_{n}\right)$, one has $\lim _{n \rightarrow \infty} d\left(x_{n}, F(x)\right)=0$.

Then $F$ has a fixed point.

In order to apply Theorem 1 to this particular case, let us consider a subspace $Y$ of $X$ defined by $Y=\{x \in X: \alpha(x, y) \geq$ $1 \forall y \in F(x)\}$. It is clear that $Y \neq \emptyset$ because of (D3). Moreover, in view of (D2), $F$ maps $Y$ to closed subsets of $Y$. By using the function $\psi$ given in the proof of Corollary 3 , we easily see that hypotheses (i) and (B) of Theorem 1 are satisfied, which allows us to produce a Cauchy sequence $\left\{x_{n}\right\}_{n=0}^{\infty}$ in $Y$ such that the sequence $\left\{d\left(x_{n}, F\left(x_{n}\right)\right)\right\}_{n=0}^{\infty}$ converges to 0 . Of course, the limit of the sequence $\left\{x_{n}\right\}_{n=0}^{\infty}$ exists but not necessarily lies in $Y$. Under condition (D4) it is evident that that limit is a fixed point of $F$.

\section{Conflict of Interests}

The authors declare that there is no conflict of interests regarding the publication of this paper.

\section{Authors' Contribution}

All authors contributed equally and significantly in writing this paper. All authors read and approved the final paper.

\section{Acknowledgments}

This work was funded by the Deanship of Scientific Research (DSR), King Abdulaziz University, Jeddah, under Grant no. (130-85-D1435). The authors, therefore, acknowledge with thanks DSR technical and financial support.

\section{References}

[1] R. P. Agarwal, M. Meehan, and D. O'Regan, Fixed Point Theory and Applications, Cambridge University Press, Cambridge, Mass, USA, 2004. 
[2] M. Balaj, "A fixed point-equilibrium theorem with applications," Bulletin of the Belgian Mathematical Society, vol. 17, no. 5, pp. 919-928, 2010.

[3] K. Goebel and W. A. Kirk, Topics in Metric Fixed Point Theory, vol. 28 of Cambridge Studies in Advanced Mathematics, Cambridge University Press, Cambridge, UK, 1990.

[4] A. Granas and J. Dugundji, Fixed Point Theory, Springer Monographs in Mathematics, Springer, New York, NY, USA, 2003.

[5] M. A. Khamsi and W. A. Kirk, An Introduction to Metric Spaces and Fixed Point Theory, Pure and Applied Mathematics, John Wiley and Sons, New York, NY, USA, 2001.

[6] S. B. Nadler Jr., "Multi-valued contraction mappings," Pacific Journal of Mathematics, vol. 30, pp. 475-488, 1969.

[7] J. T. Markin, "A fixed point theorem for set valued mappings," Bulletin of the American Mathematical Society, vol. 74, pp. 639$640,1968$.

[8] T. H. Chang, "Common fixed point theorems for multivalued mappings," Mathematica Japonica, vol. 41, no. 2, pp. 311-320, 1995.

[9] L. Ćirić, "Multi-valued nonlinear contraction mappings," Nonlinear Analysis: Theory, Methods \& Applications, vol. 71, no. 7-8, pp. 2716-2723, 2009.

[10] L. Ćirić, "Fixed point theorems for multi-valued contractions in complete metric spaces," Journal of Mathematical Analysis and Applications, vol. 348, no. 1, pp. 499-507, 2008.

[11] P. Z. Daffer and H. Kaneko, "Fixed points of generalized contractive multi-valued mappings," Journal of Mathematical Analysis and Applications, vol. 192, no. 2, pp. 655-666, 1995.

[12] Y. Feng and S. Liu, "Fixed point theorems for multi-valued contractive mappings and multi-valued Caristi type mappings," Journal of Mathematical Analysis and Applications, vol. 317, no. 1, pp. 103-112, 2006.

[13] J. Jachymski, "On Reich's question concerning fixed points of multimaps," Unione Matematica Italiana: Bollettino A: Serie VII, vol. 9, no. 3, pp. 453-460, 1995.

[14] D. Klim and D. Wardowski, "Fixed point theorems for setvalued contractions in complete metric spaces," Journal of Mathematical Analysis and Applications, vol. 334, no. 1, pp. 132139, 2007.

[15] A. Latif and A. A. N. Abdou, "Multivalued generalized nonlinear contractive maps and fixed points," Nonlinear Analysis: Theory, Methods \& Applications, vol. 74, no. 4, pp. 1436-1444, 2011.

[16] A. Latif and D. T. Luc, "Variational relation problems: existence of solutions and fixed points of contraction mappings," Fixed Point Theory and Applications, vol. 315, pp. 1-10, 2013.

[17] A. Latif and I. Tweddle, "Some results on coincidence points," Bulletin of the Australian Mathematical Society, vol. 59, no. 1, pp. 111-117, 1999.

[18] N. Mizoguchi and W. Takahashi, "Fixed point theorems for multivalued mappings on complete metric spaces," Journal of Mathematical Analysis and Applications, vol. 141, no. 1, pp. 177$188,1989$.

[19] T. Suzuki, "Mizoguchi-Takahashi's fixed point theorem is a real generalization of Nadler's," Journal of Mathematical Analysis and Applications, vol. 340, no. 1, pp. 752-755, 2008.

[20] W.-S. Du and F. Khojasteh, "New results and generalizations for approximate fixed point property and their applications," Abstract and Applied Analysis, vol. 2014, Article ID 581267, 9 pages, 2014. 


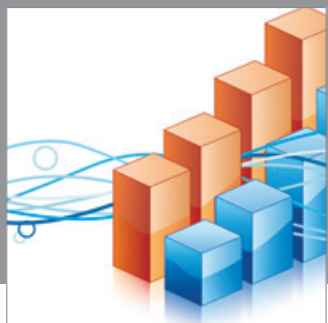

Advances in

Operations Research

mansans

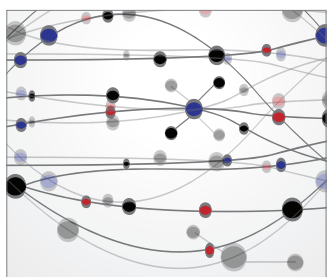

The Scientific World Journal
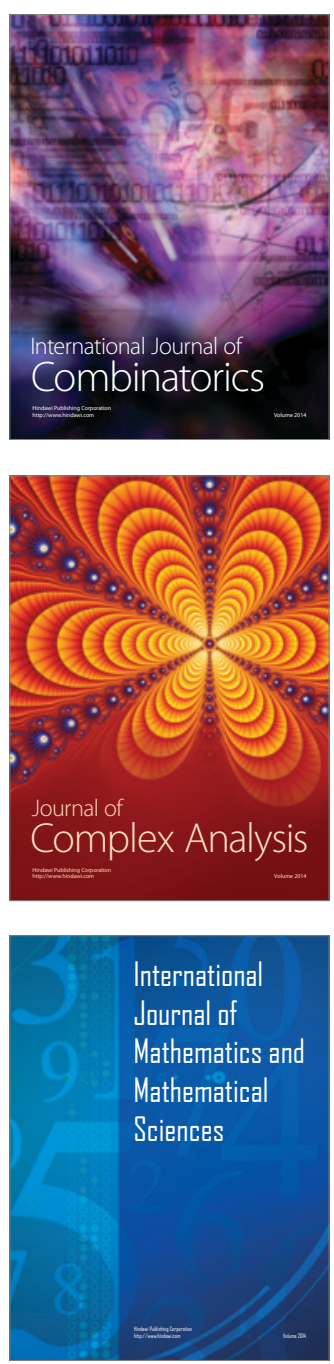
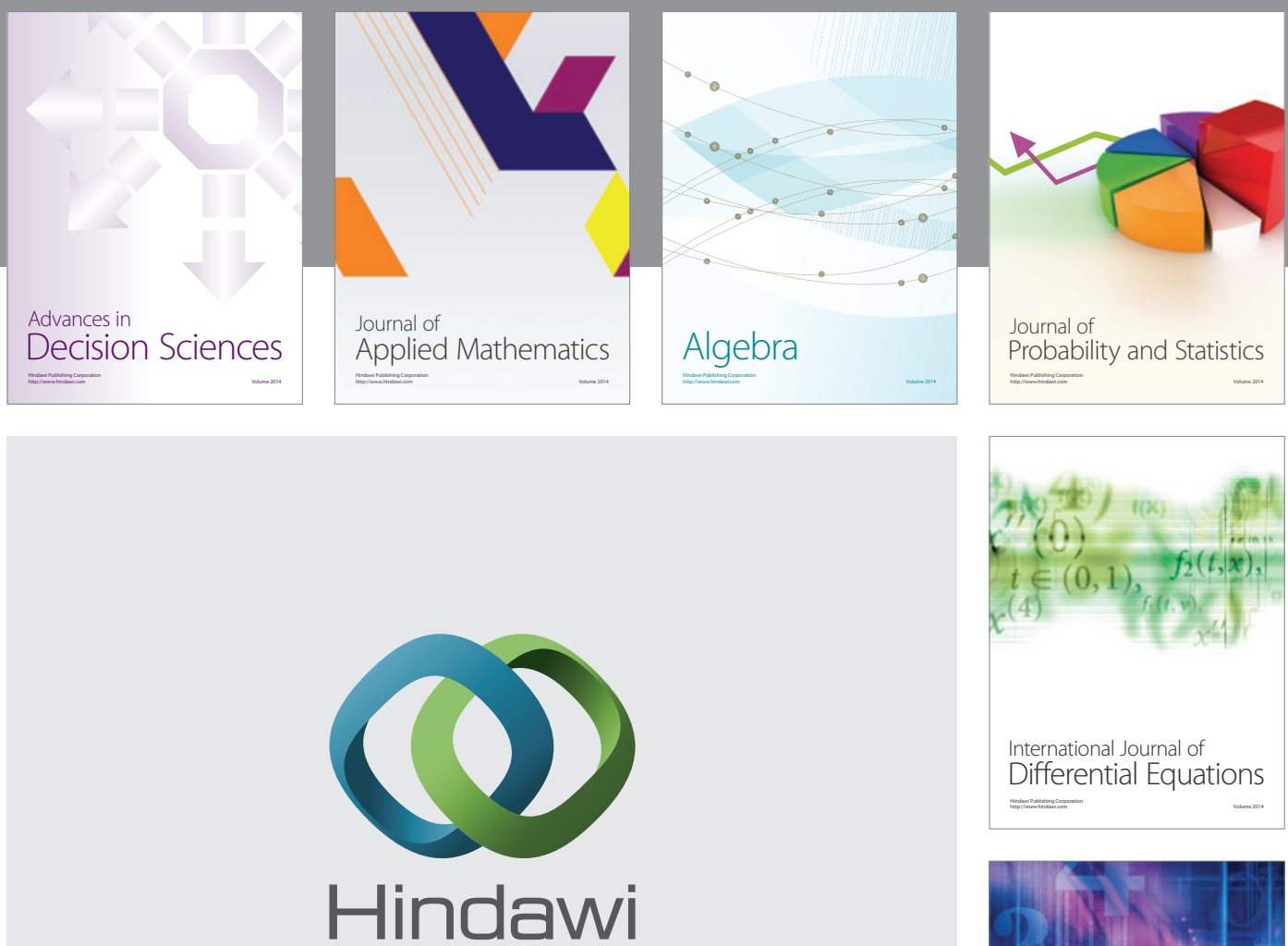

Submit your manuscripts at http://www.hindawi.com
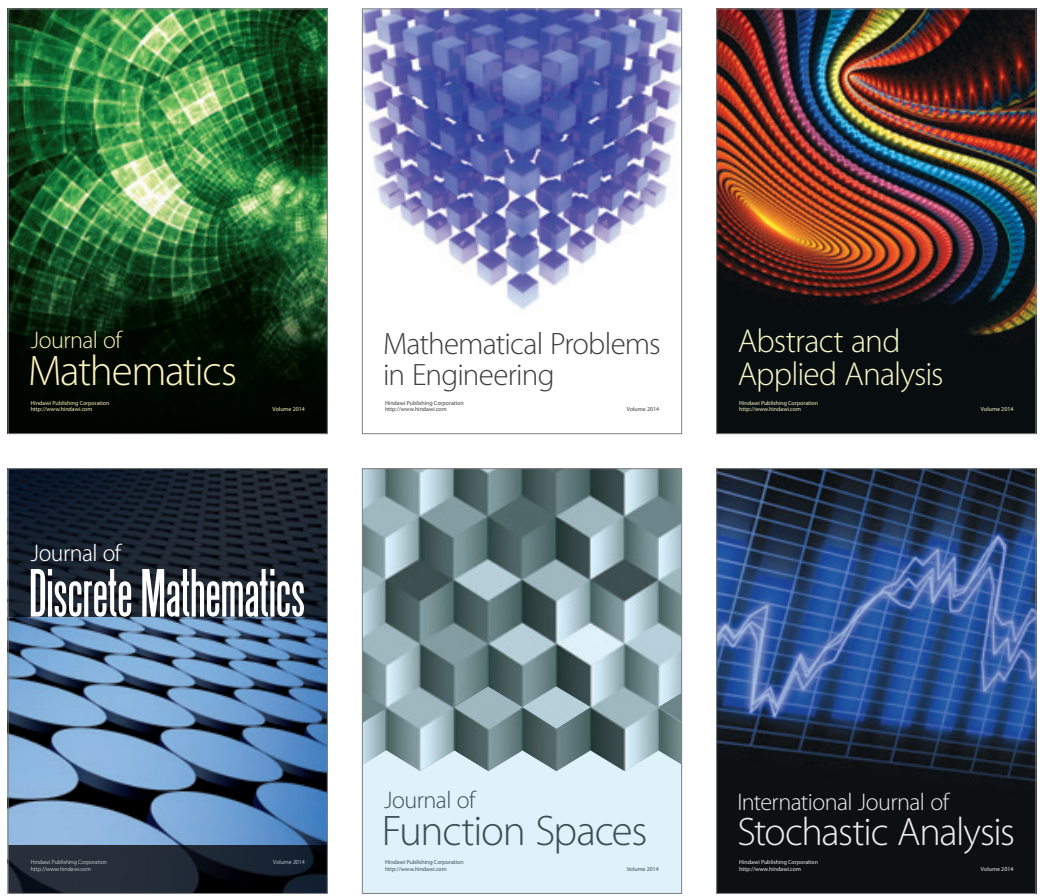

Journal of

Function Spaces

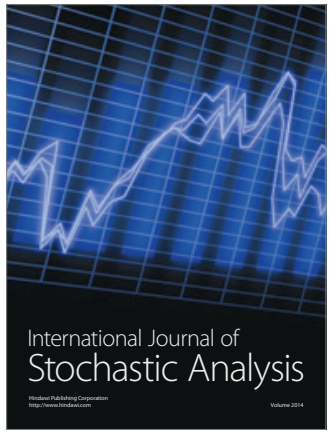

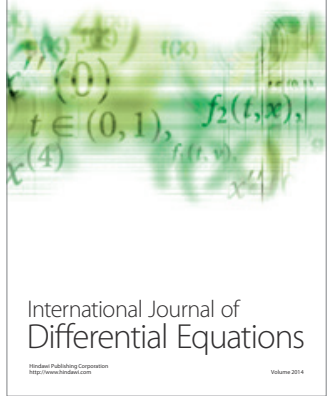
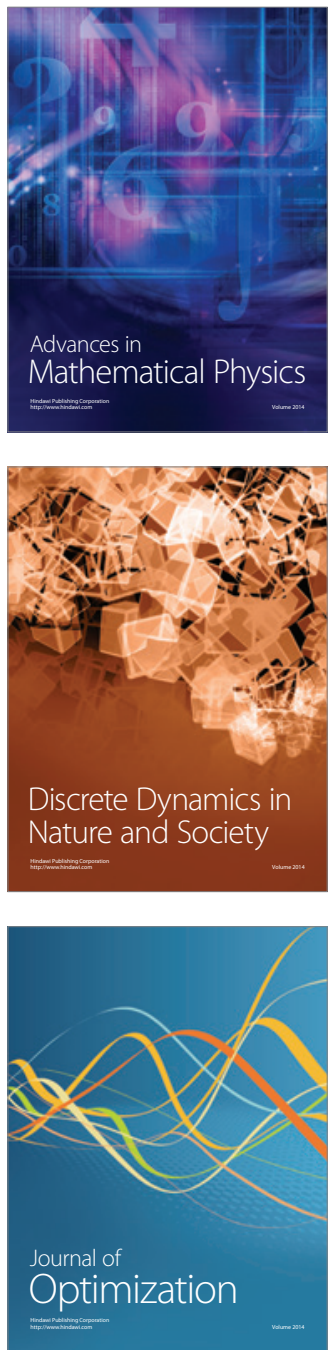